\title{
Thermal energy storage to minimize cost and improve efficiency of a polygeneration district energy system in a real- time electricity market
}

Jong Suk Kim, Wesley J. Cole, Kriti Kapoor, Jose L. Mojica, John D. Hedengren, Thomas F. Edgar, Kody M. Powell

October 2016

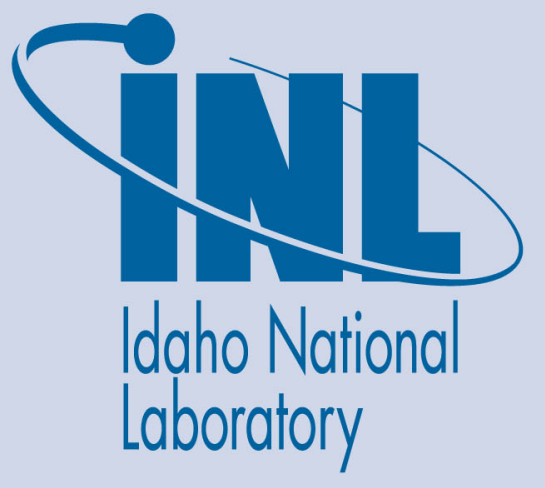

The INL is a U.S. Department of Energy National Laboratory operated by Battelle Energy Alliance 


\section{Thermal energy storage to minimize cost and improve efficiency of a polygeneration district energy system in a real-time electricity market}

Jong Suk Kim, Wesley J. Cole, Kriti Kapoor, Jose L. Mojica, John D. Hedengren, Thomas F. Edgar, Kody M. Powell

October 2016

Idaho National Laboratory Idaho Falls, Idaho 83415

http://www.inl.gov

Prepared for the U.S. Department of Energy Office of Nuclear Energy Under DOE Idaho Operations Office

Contract DE-AC07-05ID14517 
Kody M. Powell, Ph.D. (Corresponding Author)

The University of Utah

Jong Suk Kim, Ph.D.

Idaho National Labs

Kriti Kapoor, Ph.D.

Freescale Semiconductor

\section{Jose Mojica}

ExxonMobil

\section{John D. Hedengren, Ph.D.}

Brigham Young University

Department of Chemical Engineering

\section{Thomas F. Edgar, Ph.D.}

The University of Texas at Austin Department of Chemical Engineering 
Abstract - Distributed energy systems can produce low-cost utilities for large energy

34 networks, but can also be a resource for the electric grid by their ability to ramp production or to store thermal energy by responding to real-time market signals. In this work, dynamic optimization exploits the flexibility of thermal energy storage by determining optimal times to store and extract excess energy. This concept is applied to a polygeneration distributed energy system with combined heat and power, district heating, district cooling, and chilled water thermal energy storage. The system is a university campus responsible for meeting the energy needs of tens of thousands of people. The objective for the dynamic optimization problem is to minimize cost over a 24-hour period while meeting multiple loads in real time. The paper presents a novel algorithm to solve this dynamic optimization problem with energy storage by decomposing the problem into multiple static mixed-integer nonlinear programming (MINLP) problems. Another innovative feature of this work is the study of a large, complex energy network which includes the interrelations of a wide variety of energy technologies. Results indicate that a cost savings of $16.5 \%$ is realized when the system can participate in the wholesale electricity market.

- A district energy system with central cooling, heating, and electricity generation is studied

- The system is optimized over 24 hours using thermal energy storage to shift loads

- A novel static/dynamic decomposition is used to solve the dynamic optimization problem

- Scenarios with buying and selling electrical power in a real-time market are considered

- Overall, a savings of $16.5 \%$ is achieved for a one-year period

\section{INTRODUCTION}

Concern about energy scarcity and global climate change has been a driving force for the development of new energy technologies with an increasing emphasis on emissions reduction and improved efficiency. This has led to a diverse mix of energy resources and the growing

59 technological challenge to integrate all of these resources into reliable systems. These systems

60 must ensure that varying consumer demand for energy is met, while simultaneously managing

61 transient and intermittent (in the case of solar and wind) energy supply. As more diverse energy

62 technologies become connected to the grid, managing it becomes more difficult. These 
63 technological challenges have led to the implementation of the smart grid: an electric grid with 64 enhanced flow of information, which enables intelligent, automated decisions to be made, ensuring robust and efficient energy distribution [1,2]. The smart grid, where many different energy technologies interact and communicate with each other, introduces opportunities for system optimization [3,4]. Optimization can improve overall system performance by allowing intelligent decisions to be made, so that a global objective is achieved from the individual components of the system [5].

The transient nature of both supply and demand of energy has also led to increased development and deployment of energy storage technologies, which help to alleviate supply and demand mismatch [6,7]. In the context of the smart grid, energy storage technologies provide enhanced flexibility, which can be best exploited using optimization. Thermal energy storage (TES) is one of the few energy storage technologies that has proven to be an economically feasible large-scale storage solution [8-13]. Unlike electrical energy storage, TES stores thermal energy, and must be located in close proximity to the thermal loads which it services, such as in a district energy system, where electric or thermal power may be generated, distributed, and consumed in a small geographical area $[14,15]$. These energy systems are an excellent test bed for smart grid technologies. Unlike the smart grid, however, district energy systems may incorporate more than electrical distribution; they may include district heating and district cooling, where heating and cooling are generated at central locations and distributed to the surrounding area. These systems also extend the opportunities for optimization beyond electrical generation and distribution, creating the opportunity for a smart and diverse energy network 84 which provides energy for electrical, heating, and cooling demands. While there is more opportunity for optimization in these systems, the optimization problems themselves are more complex and require models of a diverse range of systems. They also have additional constraints which must be adhered to, including meeting other (non-electrical) loads, such as heating and cooling.

District energy systems take advantage of economies of scale in order to efficiently and cost-effectively provide heating, cooling, or electricity for an immediate surrounding area. Many

91 buildings can be supplied by large centrally-located generation equipment, rather than smaller

92 individual units for each building [16-19]. Because of the large scales involved in these systems, 
93 optimization is a valuable energy and cost saving tool [20-24]. In addition to the economies of

94 scale available in central utility generation, a similar benefit is available for energy storage.

95 Because the generation and distribution are already in place, large-scale TES can also be readily

96 implemented in district heating and cooling systems [21,25,26]. The addition of TES provides

97 low-cost energy storage, giving the system the ability to shift supply and demand of energy. TES

98 can be used to avoid peak electricity rates by using electric chillers to generate cooling during

99 off-peak hours, when electricity costs are lower [27]. This alleviates the cooling needs of the

100 campus during peak hours. The addition of TES to a district heating or cooling system also

101 provides additional degrees of freedom, which can be exploited by optimization. This means the

102 system can be optimized on a dynamic basis, and loads can be shifted temporally so that cost or

103 energy usage can be minimized over a finite time interval [14,28].

104 District energy systems may also be equipped with combined heat and power (CHP),

105 where electrical power is produced onsite. The waste heat from power production is then used in 106 the district heating loop, making this setup very efficient [29,30]. The opportunities for 107 optimization in CHP systems is also tremendous. If power generation capacity exceeds demand, 108 selling excess power (if regulations permit) can be a source of revenue to help offset operation 109 and fuel costs. Optimization problems are often solved to determine the best CHP plant operation 110 for economic dispatch [31-34]. The addition of TES into a CHP district energy systems provides 111 additional flexibility [25,35]. TES can be used to shift loads and free up generation capacity 112 during peak electrical hours, when prices are highest and maximum revenue can be generated.

\section{2. SYSTEM OVERVIEW}

114 This district energy system located at the University of Texas at Austin and detailed in 115 this study contains all the elements discussed above: CHP, district heating, district cooling, and 116 TES. The CHP plant utilizes a gas turbine (43.1 $\mathrm{MW}_{\mathrm{e}}$ capacity) for primary power generation. 117 The exhaust gas from this turbine is fed to a heat recovery steam generator (HRSG), which 118 converts the waste energy to superheated steam. The HRSG is also equipped with duct burners, 119 where additional gas can be burned to ensure that the appropriate superheated steam 120 temperatures are always reached. This high pressure superheated steam (at 30 bar) is then 121 throttled to 11 bar for distribution to campus. During this process, additional power is generated 122 using an extraction steam turbine, which generates power during steam expansion. In the turbine, 
123 enough medium pressure (11 bar) steam is extracted to meet heating demands. The rest is 124 dropped to near ambient pressure at saturation conditions. With the combination of a gas and 125 steam turbine, the power plant can effectively operate in combined cycle. The plant is a 126 combined cycle and a tri-generation system, providing electricity, heating, and cooling.

127 The system is equipped with an auxiliary boiler, which burns natural gas and produces 128 additional superheated steam at 30 bar. The steam output from the HRSG and the auxiliary boiler 129 is combined in a high pressure header before steam is fed to the steam turbine. The auxiliary 130 boiler is necessary during winter months when HRSG steam generation is insufficient to meet 131 campus heating loads. The boiler can also be used to increase power production in the steam 132 turbine.

133 In addition to providing electricity directly to campus, the CHP plant must also power 134 nine electric chillers, which are used to produce chilled water to meet the campus's cooling 135 needs. The chillers are each located in a central station, which house three chillers each. Each 136 station is equipped with a set of cooling towers, which provide cooling water for heat rejection in 137 each chiller as well as multiple chilled and cooling water pumps. The combined electricity 138 consumption from the cooling system can be significant, consuming up to half the total 139 electricity output of the CHP plant.

140 In addition to the CHP plant providing power for the cooling system, the two are also 141 linked by the turbine inlet cooling (TIC) system. The TIC system is used to pre-cool the ambient 142 air before it is fed to the gas turbine [36]. This increases the air density so that both the 143 throughput and the efficiency of the gas turbine's compressor can be increased. The use of TIC 144 allows the gas turbine to produce more power. However, it also consumes power because it 145 requires additional cooling from the electrically-powered chillers. The chilled water from the 146 cooling system is distributed via pipeline to the campus buildings, where it is used for space 147 cooling. With the addition of chilled water TES, the cooling loads can be shifted, giving the 148 system an important dynamic element.

As Figure 1 shows, natural gas is used in three places: in the gas turbine, in the HRSG 150 duct burners, and in the auxiliary boiler. The gas turbine feeds exhaust gas to the HRSG which, 151 in conjunction with the auxiliary boiler, produces superheated steam that is fed to the steam 
152 turbine. The steam turbine produces additional power, while lowering the pressure of the 153 superheated steam so that it can be distributed to the campus buildings. The electrical power 154 produced from both turbines powers the campus and the cooling system, which includes cooling 155 towers, pumps, and the centrifugal chillers themselves. The cooling towers provide cooling water 156 to the chillers, which produce chilled water to distribute to campus. The TIC system also uses 157 chilled water to cool the ambient air before it is fed to the gas turbine. Because all the pieces of 158 equipment are inter-related, solving an optimization problem for the entire system is complex in 159 the formulation of the equations and verification of the solution results.

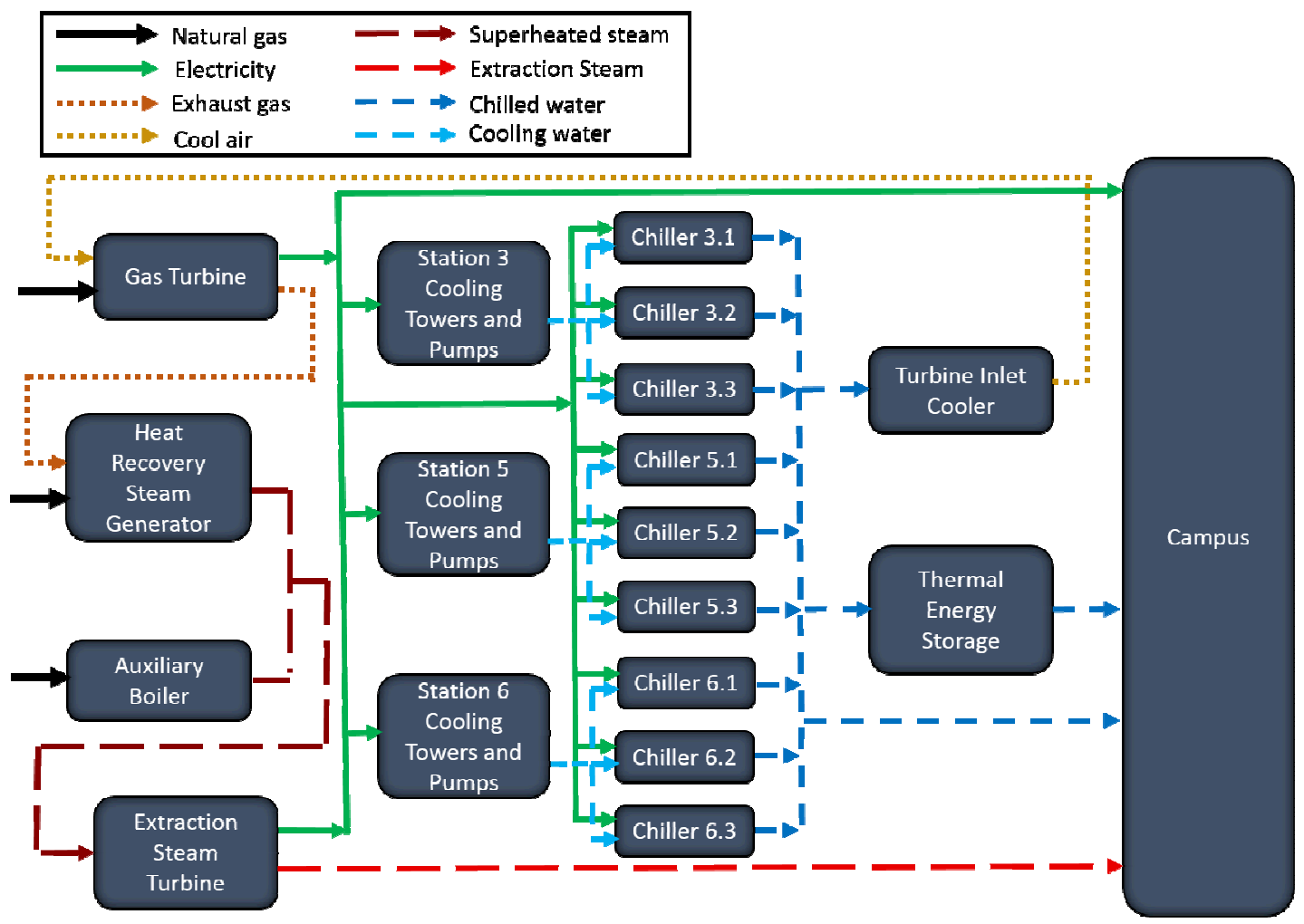

Figure 1: A diagram showing the flow of various energy streams between different pieces of equipment in the campus energy system.

\section{Model DeVElopMent}

\subsection{COOLING SYSTEM}

The cooling system is further segregated into the components of chillers, auxiliaries,

166 turbine inlet cooling, and spatially and temporally distributed thermal energy storage. Each of

167 these models is included in the overall optimization problem and strongly interact with the other

168 elements of the cooling system in nonlinear time-varying relationships. 
170

171

172

173

174

175

176

177

178

179

180

181

182

183

\subsubsection{Chillers}

With so many pieces of operating equipment, modeling the complete system proved to be a challenging undertaking. Although each component has dynamics, all but the TES system are assumed to operate at steady state. This did not significantly affect the optimization solution because the TES dynamics dominate relative to much smaller time constants for other equipment in the system. The dynamic problems is solved in one-hour time increments, well beyond the settling time of any piece of equipment, which justifies this steady state assumption for all pieces of equipment except the TES, which has several hours of storage capacity.

For the chillers, the thermodynamic model of Gordon and $\mathrm{Ng}$ is used [37,38]. This model expresses the inverse of the chiller coefficient of performance $(C O P)$ as a function of the compressor inlet temperature $\left(T_{\text {cond }}^{\text {in }}\right)$, the evaporator inlet temperature $\left(T_{\text {evp }}^{\text {out }}\right)$, the total cooling load on the chiller $(Q)$, the heat loss in the evaporator $\left(q_{\text {evp }}\right)$ and the condenser $\left(q_{\text {cond }}\right)$, as well as the heat transfer coefficients in the evaporator $\left(M_{\text {evp }}\right)$ and condenser $\left(M_{\text {cond }}\right)$. This relationship is shown in (1).

$$
\begin{aligned}
& \frac{1}{C O P}=-1+\left(\frac{T_{\text {cond }}^{\text {in }}}{T_{e}^{\text {out }}}\right)+\left(\frac{1}{Q}\right)\left(\frac{q_{\text {evp }} T_{\text {cond }}^{\text {in }}}{T_{\text {evp }}^{\text {out }}}-q_{\text {cond }}\right) \\
& +\left(\frac{1}{Q}\right)\left(\frac{q_{\text {evp }}}{M_{\text {cond }} T_{\text {evp }}^{\text {out }}}\right)\left(\frac{q_{\text {evp }} T_{\text {cond }}^{\text {in }}}{T_{\text {evp }}^{\text {out }}}-q_{\text {cond }}\right) \\
& +\left(\frac{Q}{T_{\text {evp }}^{\text {out }}}\right)\left(\frac{T_{\text {cond }}^{\text {in }}}{T_{\text {evp }}^{\text {out }}}\right)\left(\frac{1}{M_{\text {cond }}}+\frac{1}{M_{\text {evp }}}\right) \\
& \frac{q_{\text {cond }}}{M_{\text {evp }}}+\frac{q_{\text {evp }} T_{\text {cond }}^{\text {in }}}{T_{\text {evp }}^{\text {out }} M_{\text {cond }}}+\left(\frac{T_{\text {cond }}^{\text {in }} q_{\text {evp }}}{T_{\text {evp }}^{\text {out }}}-q_{\text {cond }}\right)\left(\frac{1}{T_{\text {cont }}^{\text {out }}}+\frac{1}{M_{\text {evp }}}\right) \\
& \left.+\frac{\left(M_{\text {cond }}\right.}{M}\right)
\end{aligned}
$$




$$
\begin{aligned}
& P_{c h}=\frac{Q}{C O P}=-Q+\left(\frac{T_{\text {cond }}^{\text {in }}}{T_{\text {evp }}^{\text {out }}}\right) Q+\left(\frac{q_{e} T_{\text {cond }}^{\text {in }}}{T_{\text {eup }}^{\text {out }}}-q_{\text {cond }}\right) \\
& +\left(\frac{q_{\text {evp }}}{M_{\text {cond }} T_{\text {evp }}^{\text {out }}}\right)\left(\frac{q_{\text {evp }} T_{\text {cond }}^{\text {in }}}{T_{\text {evp }}^{\text {out }}}-q_{\text {cond }}\right)+\left(\frac{Q^{2}}{T_{\text {evp }}^{\text {out }}}\right)\left(\frac{T_{\text {cond }}^{\text {in }}}{T_{\text {evp }}^{\text {out }}}\right)\left(\frac{1}{M_{\text {cond }}}+\frac{1}{M_{\text {evp }}}\right) \\
& +Q \frac{\frac{q_{\text {cond }}}{M_{\text {evp }}}+\frac{q_{\text {evp }} T_{\text {cond }}^{\text {in }}}{T_{\text {evp }}^{\text {out }} M_{\text {cond }}}+\left(\frac{T_{\text {cond }}^{\text {in }} q_{\text {evp }}}{T_{\text {evp }}^{\text {out }}}-q_{\text {cond }}\right)\left(\frac{1}{M_{\text {cond }}}+\frac{1}{M_{\text {evp }}}\right)}{T_{\text {evp }}^{\text {out }}}
\end{aligned}
$$

The model terms are arranged so that the model prediction is linearly dependent on the unknown parameters and linear least squares can be used. The fit for Chiller 6.1 is shown in Figure 2 with an $\mathrm{R}^{2}$ of 0.995 , indicating that the model in (2) provides an excellent fit to the data.

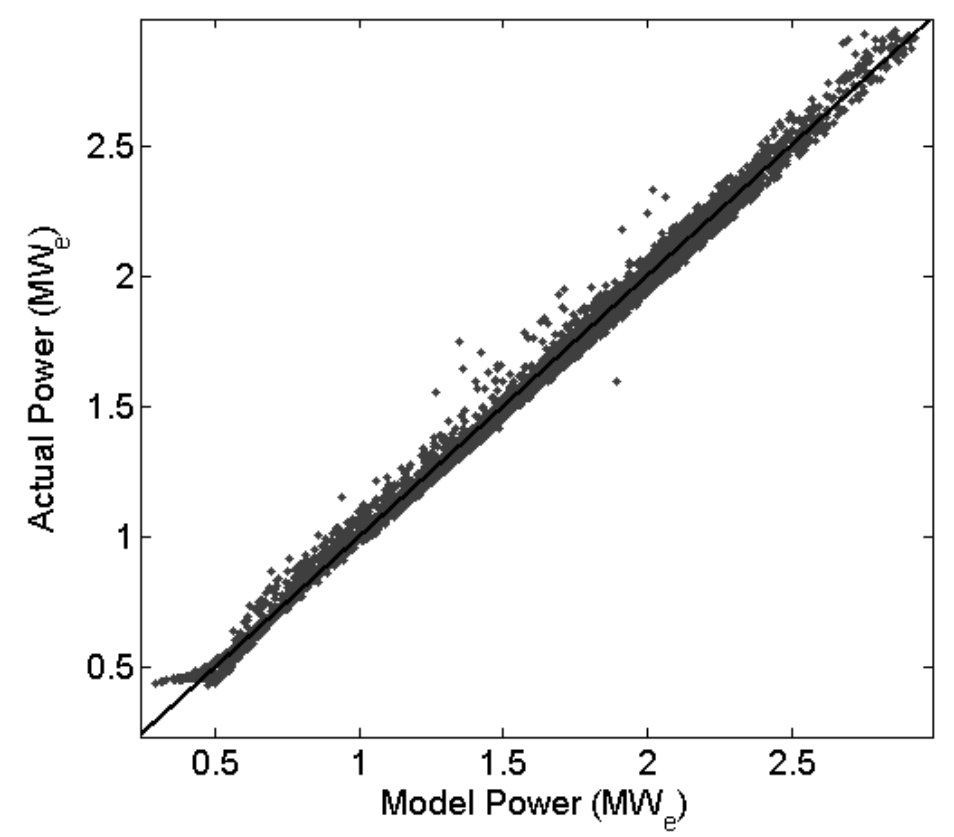

Figure 2: Parity plot illustrating the quality of the model fit for a chiller.

192 chillers as 1/COP vs. chiller load using the models developed in Equation 1. Figure 4 shows the 193 chiller power consumption as a function of chiller load as detailed in Equation 2. As these 194 figures illustrate, there is a clear benefit to optimizing the system. Because some chillers perform 195 so much more efficiently than others and at different loads, it is beneficial to distribute the load 
196 optimally over the chillers. This optimal sequencing over time with chiller loading can be 197 determined by minimizing the global cost of operation [14].

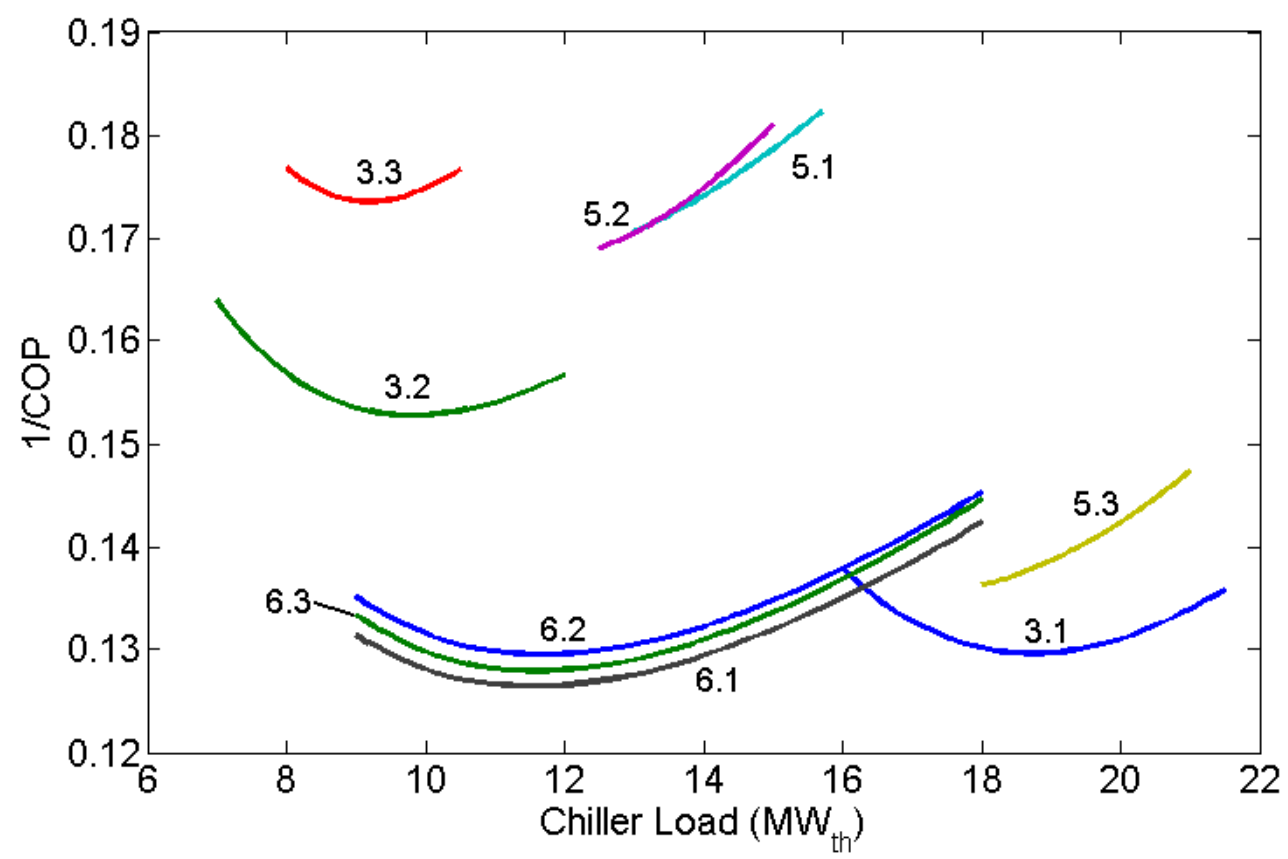

198

199

Figure 3: 1/COP vs. load for all chillers at a wet bulb temperature of ${ }^{\circ} \mathrm{C}$.

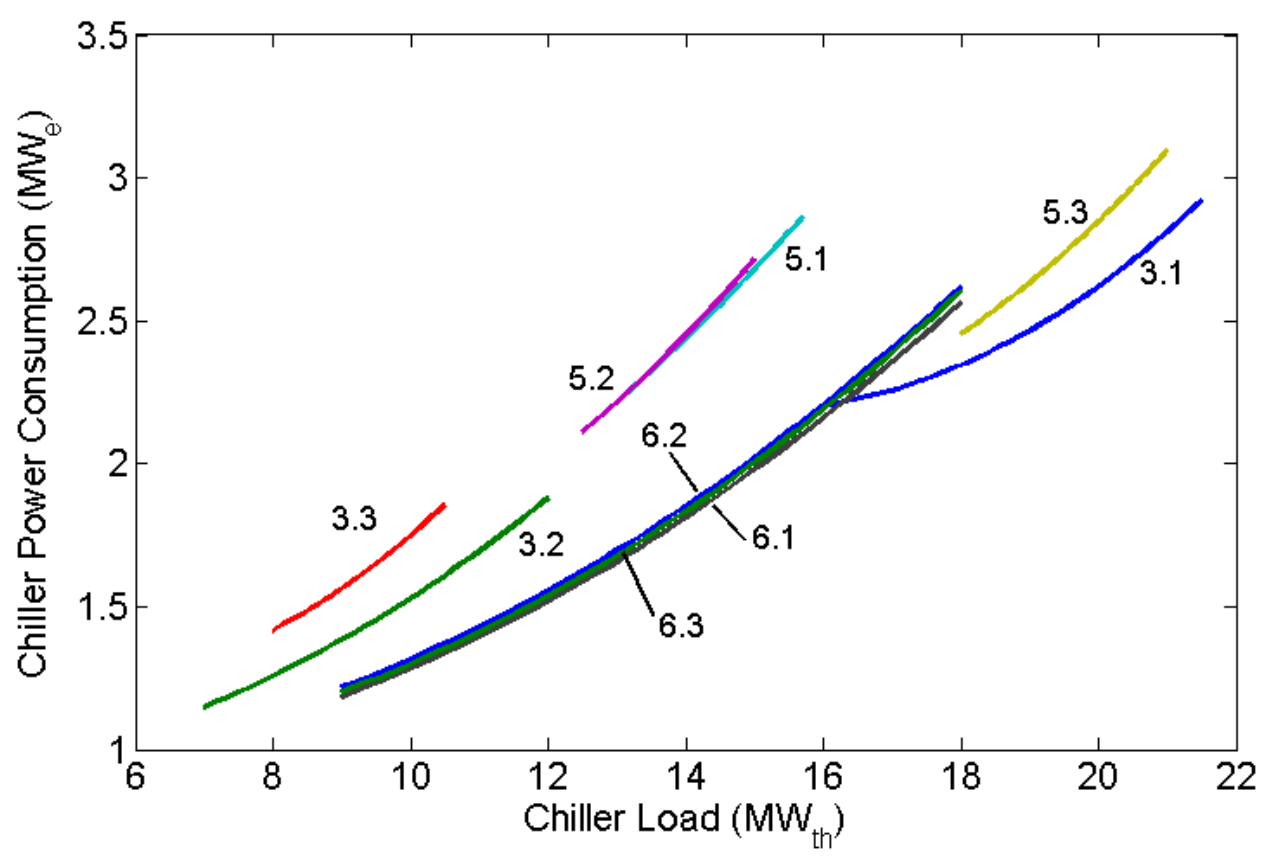


The cooling system auxiliaries (cooling towers and pumps) are challenging to model

205 because of many different components ( 3 fans for each cooling tower and up to 18 pumps per 206 station) and unmeasured individual flows for each pump. In order to simplify the modeling task, 207 an empirical model is used to capture the total auxiliary power consumption for each station as a 208 function of: the total cooling load for the station $\left(Q_{s}\right)$, in addition to the ambient dry bulb 209 temperature $\left(T_{D B}\right)$, wet bulb temperature $\left(T_{W B}\right)$, and relative humidity $\left(R_{H}\right)$. A quadratic 210 polynomial model is used for the multivariable empirical relationships. This model is shown in 211 Equation 3, where $X$ represents a vector of model inputs $\left(Q_{s}, T_{D B}, T_{W B}\right.$, and $\left.R_{H}\right)$, and $A$ (a matrix), $212 B$ (a vector), and $C$ (a scalar) represent model fitting parameters.

$$
P_{a u x}=X^{T} A X+B X+C
$$

The fit for the Station 6 auxiliaries is shown in Figure 5. As the figure demonstrates, this 214 simplified empirical model doesn't explain the data quite as well as the performance of the 215 individual chiller models indicating that the model form is incorrect or there are stochastic 216 uncertainties. However, the fit, with an $\mathrm{R}^{2}$ value of 0.903 provides reasonable representation of 217 chiller power consumption.

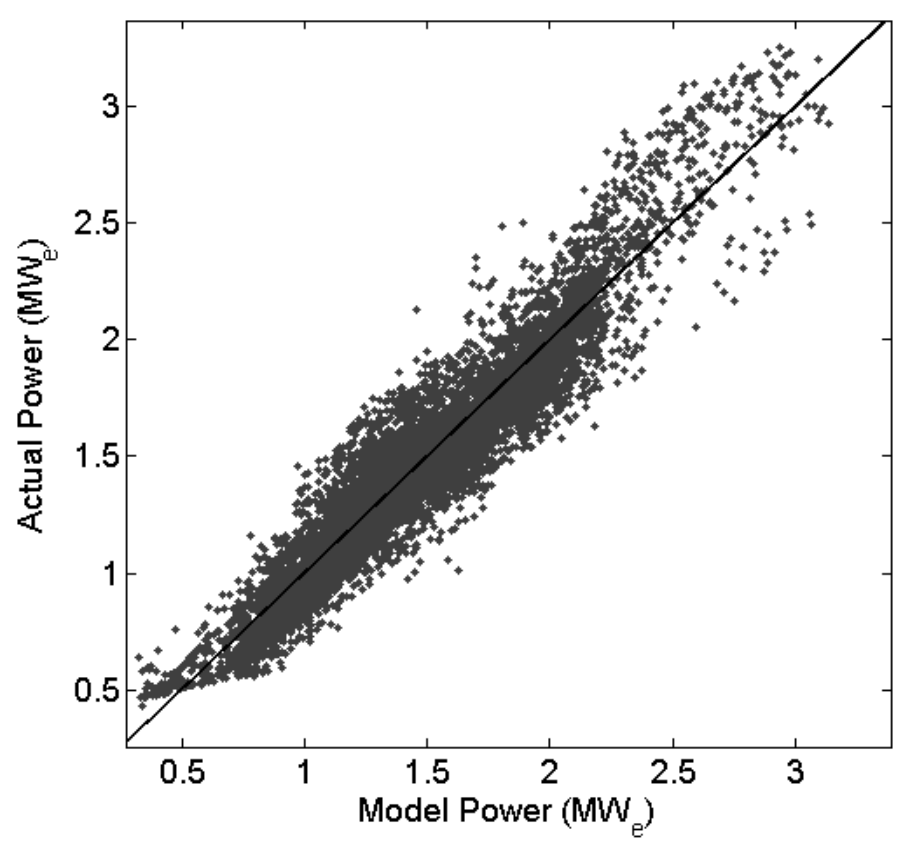

Figure 5: Parity plot for the auxiliary power consumption model for Cooling Station 6. 
The TIC system model is based on an energy balance between the chilled water and the 222 air stream that the chilled water cools. For optimization purposes, the chiller loads are adjustable 223 decision variables, so it is desirable to represent the TIC system in terms of cooling load as well. 224 The TIC model then becomes:

$$
Q_{T I C}=W_{a i r} C_{p c}\left(T_{D B}-T_{i}\right)
$$

225 where $Q_{T I C}$ is the cooling energy consumed by the turbine inlet air cooler, $W_{\text {air }}$ is the air flow 226 rate, $C_{p c}$ is the average heat capacity of the air (with $c$ in the subscript indicating lower 227 temperature), and $T_{i}$ is the temperature entering the gas turbine.

\subsubsection{THERMAL ENERGY STORAGE}

Because the optimization problem is solved on an hourly basis, a discrete-time dynamic model (5), which tracks the total energy stored $\left(E_{T E S}\right)$ at each hour $i$, is used for the TES system.

231 When the total cooling produced by the chillers at time $i$, exceeds the sum of the campus demand $232\left(L_{C}\right)$ and the TIC cooling load, the system charges. The TES system is also subjected to energy 233 losses $\left(E_{\text {loss }}\right)$ due to heat transfer and pumping, which are assessed during charging at $4 \%$ of the 234 energy stored during that period. The charging rate $\left(Q_{T E S, i}\right)$ is the sum of all the chillers, minus 235 the campus load and the TIC load at time $i$. The subscript $j$ refers to the chiller index.

$$
\begin{gathered}
E_{T E S, i}=E_{T E S, i-1}+\left(Q_{T E S, i}-E_{\text {loss }, i}\right) \Delta t \\
Q_{T E S, i}=\sum_{j} Q_{i, j}-\left(L_{C, i}+Q_{T I C, i}\right)
\end{gathered}
$$


The models for the CHP system are developed and fit by using steady-state first 242 principles models [39]. Model parameters are identified using linear or nonlinear least squares, 243 depending on the model. The power generated by the gas turbine $\left(P_{G T}\right)$ is a function of the air 244 flow, the fuel flow $\left(W_{f, G T}\right)$, the inlet temperature, the temperature at the exit of the compressor $245\left(T_{d}\right)$, the firing temperature $\left(T_{f}\right)$, and the exhaust temperature $\left(T_{e}\right)$. The various sections of the gas 246 turbine are shown in Figure 6. The power output of the gas turbine is given in (7), where $C_{p h}$ is 247 the average high temperature heat capacity of the air and gas mixture.

$$
P_{G T}=\left[\left(W_{a i r}+W_{f, G T}\right) C_{p h}\left(T_{f}-T_{e}\right)-W_{a i r} C_{p c}\left(T_{d}-T_{i}\right)\right]
$$

Fuel flow

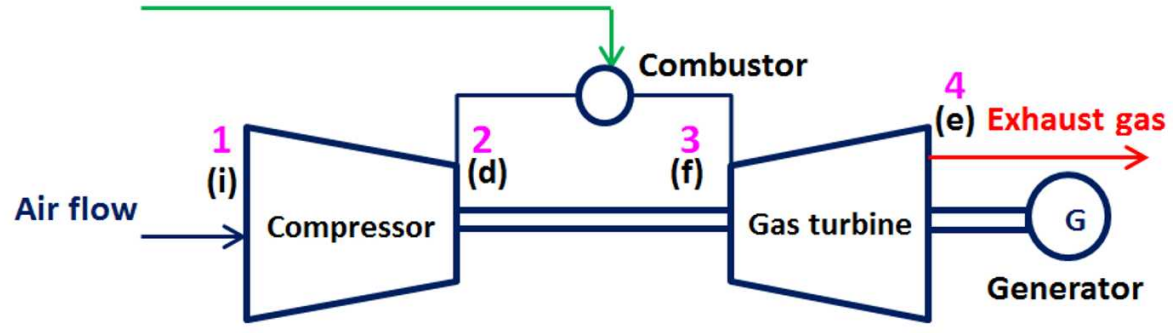

Figure 6: Schematic of the gas turbine, available from. compressor efficiency.

$$
T_{d}=T_{i}\left(1+\frac{x_{c}-1}{\eta_{c}}\right)
$$

252 where $x_{c}$ is defined in (9), where $P R$ is the compression ratio, $\gamma_{c}$ is the cold-end ratio of specific 253 heats, and $W_{\text {air, } n}$ is the air flow at nominal operating conditions (full load).

$$
x_{c}=\left(P R \frac{W_{\text {air }}}{W_{\text {air }, n}}\right)^{\frac{\gamma_{c}-1}{\gamma_{c}}}
$$

254 The firing temperature is determined by an energy balance on the combustion chamber.

255 The firing temperature is given in (10), where $W_{f, G T}$ is the fuel flow rate, $\eta_{c o m b, G T}$ is the combustor 256 efficiency, and LHV is the lower heating value of the fuel. 


$$
T_{f}=T_{d}+\left(\frac{\eta_{c o m b, G T} L H V}{C_{p h}}\right)\left(\frac{W_{f, G T}}{W_{f, G T}+W_{\text {air }}}\right)
$$

The exhaust temperature is given in (11).

$$
T_{e}=T_{f}\left(1-\left(1-\frac{1}{x_{h}}\right) \eta_{t}\right)
$$

258 where $\eta_{t}$ is the turbine efficiency and $x_{h}$ is defined as (12):

$$
x_{h}=\left(P R \frac{W_{f, G T}+W_{a i r}}{W_{f n, G T}+W_{n}}\right)^{\frac{\gamma_{h}-1}{\gamma_{h}}}
$$

259 where $\gamma_{\mathrm{h}}$ is the ratio of specific heats.

The air flow is not determined directly, but rather is determined by adjusting the angle of 261 the inlet guide vanes $\left(\theta_{I G V}\right)$, as shown in (13), where $P_{a}$ is the ambient pressure, $\Delta P_{T I C}$, is the 262 pressure drop across the TIC, $P_{a 0}$ is the reference pressure, $T_{a 0}$ is the reference temperature, and $263 \theta_{\max }$ and $\theta_{0}$ are the maximum and reference guide vane angles, respectively.

$$
W_{\text {air }}=\frac{P_{a}-\Delta P_{T I C}}{P_{a 0}} \sqrt{\frac{T_{a 0}}{T_{D B}}} \frac{\sin \left(\theta_{I G V}-\theta_{0}\right)}{\sin \left(\theta_{\max }-\theta_{0}\right)}
$$
265 the model fit compared to data. The $\mathrm{R}^{2}$ value of 0.98 indicates a good model fit.

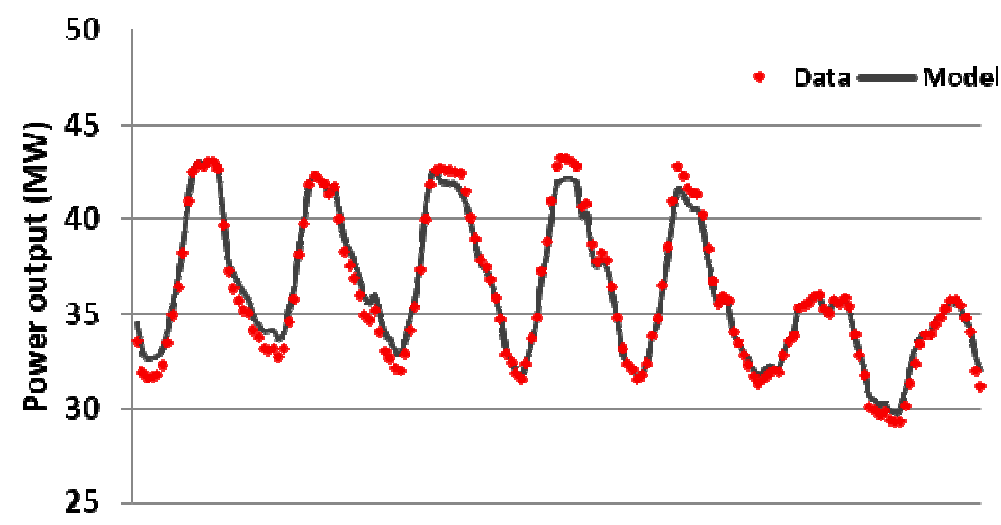

Figure 7: Model validation for the gas turbine model. 


\subsubsection{HeAt Recovery SteAm Generator}

The HRSG is composed of several sections, where heat is transferred from the gas turbine exhaust gas to make superheated steam. When the gas turbine exhaust gas is not hot enough to produce the desired temperature of superheated steam or when additional superheated 272 steam is desired from the HRSG, supplemental duct burners can be fired, providing more energy.

273 The new exhaust gas temperature $\left(T_{e, H R S G i}\right)$ is given by (14), where $\eta_{\text {comb,HRSG }}$ is the duct burner 274 combustion efficiency, $W_{f, H R S G}$ is the duct burner fuel flow, and $W_{g}$ is the gas turbine exhaust 275 flow.

$$
T_{e, H R S G i}=T_{e}+\frac{L H V \eta_{c o m b, H R S G}}{C_{p h}}\left(\frac{W_{f, H R S G}}{W_{f, H R S G}+W_{g}}\right)
$$

The HRSG steam flow ( $W_{S H, H R S G}$ ) exits the HRSG at $397{ }^{\circ} \mathrm{C}$ and 30 bar. This flow is computed by an overall energy balance on the HRSG, shown in (15), where $\eta_{H R S G}$ is the HRSG 278 efficiency, $\Delta H_{F W}$ is the feedwater heater heat duty, $h_{S H}$ is the specific enthalpy of the superheated 279 steam and $h_{E C}$ is the specific enthalpy of the water entering the economizer.

$$
W_{S H, H R S G}=\frac{C_{p h} \eta_{H R S G}\left(W_{g}+W_{f, H R S G}\right)\left(T_{e, H R S G i}-T_{e, H R S G o}\right)-\Delta H_{F W}}{h_{S H}-h_{E C}}
$$

A diagram of the HRSG is shown in Figure 8.

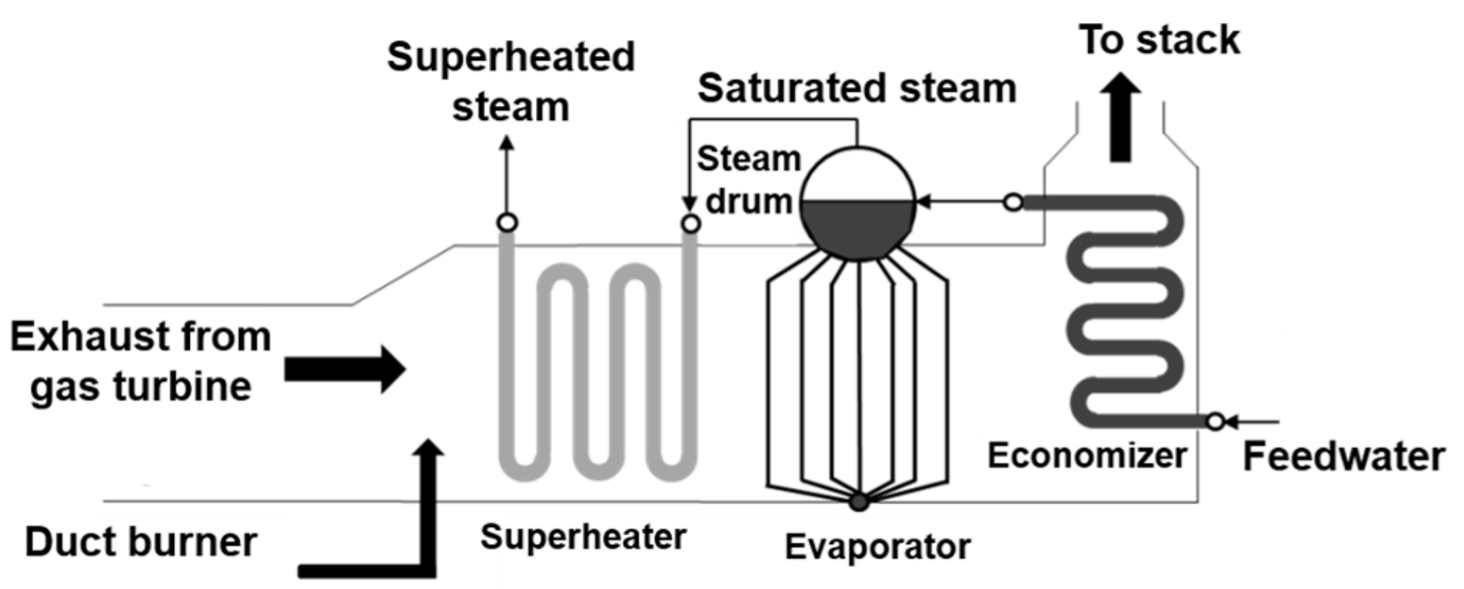

Figure 8: Diagram of the HRSG. 


\subsubsection{AuXILIARY BOILER}

The auxiliary boiler generates additional superheated steam when it is needed. The steam 287 output of the auxiliary boiler is computed by an energy balance, shown in (16), where $W_{S H, B R}$ is 288 the superheated steam flow from the boiler, $W_{f, B R}$ is the fuel flow to the boiler, and $\eta_{B R}$ is the 289 overall boiler efficiency.

$$
W_{S H, B R}=\frac{W_{f, B R}\left(\eta_{B R} L H V\right)}{h_{S H}-h_{E C}}
$$

\subsubsection{STEAM TURBINE}

The steam turbine generates electrical power from the superheated steam that is fed to it 292 from the HRSG and the auxiliary boiler. Because it is an extraction steam turbine, it can also 293 extract medium pressure steam, which is removed and sent to campus to meet the heating 294 demand. Any steam that is not removed by extraction passes through the full length of the 295 turbine and comes out near saturated vapor conditions, enabling maximum energy to be removed 296 from this stream. The steam turbine is shown in Figure 9.

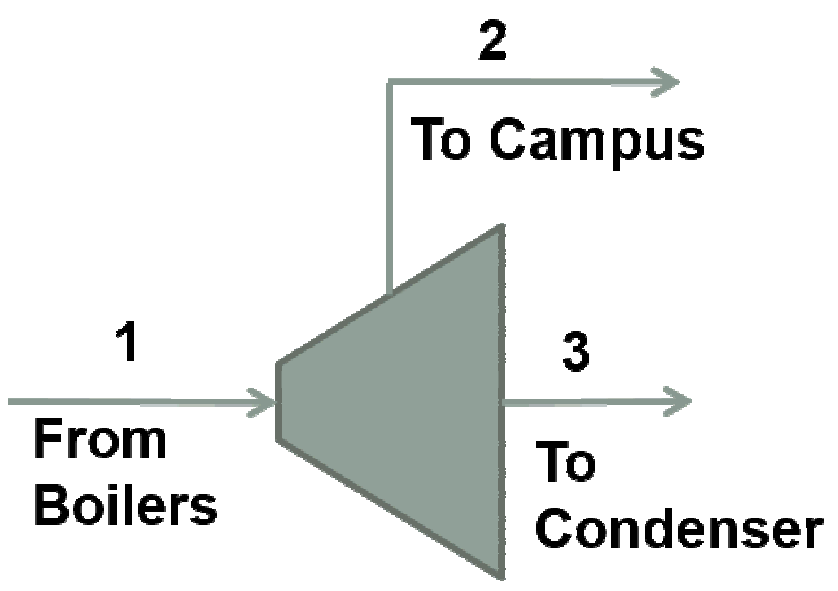

An energy balance is used on the steam turbine to calculate the power generation $\left(P_{S T}\right)$ 300 and is shown in (17), where $W_{S, E X T}$ is the extraction steam flow, $W_{S T, C O N D}$ is the condenser flow, 301 and $\eta_{S T}$ is the steam turbine efficiency. 


$$
P_{S T}=\eta_{S T}\left(W_{S H, t o t} h_{S H}-W_{S, E X T} h_{S, E X T}-W_{S, C O N D} h_{S, C O N D}\right)
$$

A mass balance on the superheated steam header yields the total steam flow entering the steam turbine (18).

$$
W_{S H, t o t}=W_{S H, \mathrm{HRSG}}+W_{S H, \mathrm{BR}}
$$

Similarly, the flow sent to the condenser is determined by a mass balance on the steam 305 turbine (19).

$$
W_{S H, t o t}=W_{S, \mathrm{EXT}}+W_{S, C O N D}
$$

306 The details of all the models pertaining to the CHP system can be explored in further detail in 307 [39].

\section{Optimization PRoblem Formulation}

The optimization problem is formulated as a smaller static problem and as a larger

310 dynamic problem with temporal resolution. The static problem is solved without the TES,

311 allowing for a much smaller and simplified problem. The addition of dynamics through the TES

312 allows energy loads to be shifted away from peak periods and dispatched on demand.

The objective for static optimization is to minimize the total cost by changing the

315 decision variables, represented by $u$, subject to changing loads, prices, and ambient conditions.

316 The objective function (20) is the total cost to operate the system including the fuel cost and the

317 cost of buying and selling power from the grid, where $C_{f}$ is the fuel cost, $P_{n e t}$ is the net power 318 exchange with the grid (positive when power is exported), and $C_{e}$ is the electricity price. 319 Operation and maintenance costs are are assumed to be constant regardless of the operational 320 strategy and do not affect the solution outcome. It is assumed that power is bought and sold at 321 wholesale prices. Often, district energy systems must deal with a local utility, which may impose 322 a different rate structure.

$$
f=C_{f}\left(W_{f, G T}+W_{f, H R S G}+W_{f, B R}\right)-C_{e} P_{n e t}
$$


323 The vector of decision variables $(u)$ is given in $(21)$, where $\delta$ are binary $(0,1)$ variables that 324 determine whether a chiller is on (value of 1 ) or off (value of 0 ).

$$
u=\left[Q_{3.1} \mathrm{~L} Q_{6.3} \delta_{3.1} \mathrm{~L} \delta_{6.3} Q_{T I C} \theta_{I G V} W_{f, G T} W_{f, \mathrm{HRSG}} W_{f, \mathrm{BR}} W_{s, E X T} P_{n e t}\right]^{T}
$$

325

326

327

328

329

330

331

332

333

The models of each component in the system described by equations (2)-(19) are represented as equality constraints in the optimization problem. The system is also subject to inequality constraints. The chillers, if on, must be operated between fixed upper and lower bounds, which given in Table 1. The binary variables are also incorporated into these constraints, which prevents them from entering the model equations, which would lead to increased nonlinearity, making the optimization problem more difficult to solve. The constraints for each chiller $(j)$ are shown in (22) with the binary constraints in (23).

$$
\begin{gathered}
\delta_{j} Q_{j, \mathrm{lo}} \leq Q_{j} \leq \delta_{j} Q_{j, \mathrm{hi}} \\
\delta_{j} \in[0,1]
\end{gathered}
$$

\section{.}

Table 1: Lower and upper bounds on chiller loads.

\begin{tabular}{|l|l|l|}
\hline Chiller & $\begin{array}{l}\text { Lower Bound } \\
\left(\mathbf{M W}_{\text {th }}\right)\end{array}$ & $\begin{array}{l}\text { Upper Bound } \\
\left(\mathbf{M W}_{\text {th }}\right)\end{array}$ \\
\hline $\mathbf{3 . 1}$ & 16 & 21.5 \\
\hline $\mathbf{3 . 2}$ & 7 & 12 \\
\hline $\mathbf{3 . 3}$ & 8 & 10.5 \\
\hline $\mathbf{5 . 1}$ & 13 & 15.7 \\
\hline $\mathbf{5 . 2}$ & 12.5 & 15 \\
\hline $\mathbf{5 . 3}$ & 18 & 21 \\
\hline $\mathbf{6 . 1}$ & 9 & 18 \\
\hline $\mathbf{6 . 2}$ & 9 & 18 \\
\hline $\mathbf{6 . 3}$ & 9 & 18 \\
\hline
\end{tabular}

The other decision variables are also constrained with upper and lower bounds. The 335 decision variables are purely continuous variables, so no binary variables are required. 


$$
u_{\mathrm{lo}} \leq u \leq u_{\mathrm{hi}}
$$

The lower and upper bounds for the remaining decision variables are shown in Table 2.

337 The heating load constraint is enforced directly on the decision variable, as the extraction steam

338 flow must be greater than or equal to the heating load $\left(L_{H}\right)$.

Table 2: Summary of constraints for other decision variables.

\begin{tabular}{|c|c|c|}
\hline Decision Variable & $\begin{array}{l}\text { Lower } \\
\text { Bound }\end{array}$ & Upper Bound \\
\hline$Q_{\text {TIC }}$ & $0\left(\mathrm{MW}_{\mathrm{th}}\right)$ & $5\left(\mathrm{MW}_{\mathrm{th}}\right)$ \\
\hline$\theta_{I G V}$ & 52 (degrees) & 88 degrees \\
\hline$W_{f, G T}$ & $0.55(\mathrm{~kg} / \mathrm{s})$ & $3.44(\mathrm{~kg} / \mathrm{s})$ \\
\hline$W_{f, \mathrm{HRSG}}$ & $0(\mathrm{~kg} / \mathrm{s})$ & $0.63(\mathrm{~kg} / \mathrm{s})$ \\
\hline$W_{f, \mathrm{BR}}$ & $.0028(\mathrm{~kg} / \mathrm{s})$ & N/A \\
\hline$W_{s, E X T}$ & $L_{H}(\mathrm{~kg} / \mathrm{s})$ & N/A \\
\hline$P_{n e t}$ & $-40\left(\mathrm{MW}_{\mathrm{e}}\right)$ & $40\left(\mathrm{MW}_{\mathrm{e}}\right)$ \\
\hline
\end{tabular}

In addition to the constraints on the decision variables, the system is also subject to

341 several other inequality constraints. The system must produce enough electricity, heating, and

342 cooling to meet each of these loads. The heating load constraint is handled in (24). The electrical

343 load constraint is given in (25), which includes the net power exported. The campus (non-

344 cooling) electric load ( $L_{E, \text { campus }}$ ), combined with the power consumed by the cooling system

345 comprise the total campus electric load. The cooling load $\left(L_{C}\right)$, which includes TIC and storage, 346 must also be met (26).

$$
\begin{gathered}
P_{G T}+P_{S T}-P_{n e t} \geq L_{E, \text { campus }}+\sum P_{c h}+\sum P_{a u x} \\
\sum_{i} Q_{i, j}-Q_{T E S} \geq L_{C}+Q_{T I C}
\end{gathered}
$$


In addition to meeting the loads, the system is subject to other inequality constraints. The 348 gas turbine firing (27) and exhaust temperatures (28) must remain below critical levels. The 349 HRSG (29) and boiler (30) steam flows must remain below maximum limits. The HRSG gas 350 temperature (after duct burning), must remain above the superheated steam temperature (31) by a 351 minimum differential $\left(\Delta T_{\min }\right)$ of $8{ }^{\circ} \mathrm{C}$. The gas (32) and steam (33) turbines must also each 352 remain within bounds.

$$
\begin{gathered}
T_{f} \leq 1107^{\circ} \mathrm{C} \\
T_{e} \leq 522^{\circ} \mathrm{C} \\
W_{\mathrm{SH}, H R S G} \leq 36.4 \mathrm{~kg} / \mathrm{s} \\
W_{\mathrm{SH}, \mathrm{BR}} \leq 63.0 \mathrm{~kg} / \mathrm{s} \\
T_{S H, H R S G}+\Delta T_{\min } \leq T_{e, H R S G i} \\
0 \leq P_{G T} \leq 44 \mathrm{MW}_{e} \\
0 \leq P_{S T} \leq 27 \mathrm{MW}_{e}
\end{gathered}
$$

353 With all of the equality and inequality constraints determined, the static optimization 354 problem is (34). Because the static problem does not include storing energy, equations (5) and 355 (6) are omitted from the problem. Furthermore, for scenarios when power exchange from the 356 grid is prohibited, $P_{n e t}$ must be equal to zero indicating that the campus operates independently 357 for power generation.

$$
\min _{u} f(u, \mathrm{~d})
$$

s.t. (2)-(34), excluding (5)-(6)

358 The problem posed above is a mixed-integer nonlinear program (MINLP), due to the 359 binary constraints in (23). These types of problems are typically more difficult to solve than 360 standard NLPs. Special solution methods are required, such as branch and bound, where certain 
361 integer constraints are fixed while a relaxed NLP problem is solved. The binary variables 362 represent which chillers are on and which are off. Because the chiller efficiencies are readily 363 available from (1), pre-determined combinations of the binary variables are tried and the best 364 solutions are kept. This removes much of the combinatorial complexity of the full MINLP and 365 enables much faster solution times. The NLP relaxations are solved using the sequential quadratic programming (SQP) algorithm in MATLAB.

\subsection{DYNAMIC OPTIMIZATION}

The dynamic optimization problem, where TES can be used to shift cooling loads (and subsequently, electrical loads), incorporates many more decision variables, where each of the decision variables defined above must be determined at every time step in the time horizon of the dynamic optimization problem. This makes the problem larger and more difficult to solve. The objective function for the dynamic problem is defined in (35), where the subscript, $i$, indicates the time. Hourly time steps are used in this case over a 24-hour period. A fixed fuel cost is used, while hourly (day-ahead market) electricity prices are used. Cooling, heating, and electrical load forecasts are assumed to be available, as has been demonstrated in prior research [40].

$$
F=\sum_{i}\left[C_{f}\left(W_{f, G T, i}+W_{f, \mathrm{HRSG}, i}+W_{f, \mathrm{BR}, i}\right)-C_{e, i} P_{n e t, i}\right](\Delta t)
$$
Including the TES system in (5) and (6), the dynamic problem is also an MINLP, albeit a much larger one than the static problem. A total of 600 decision variables are determined and the constraints satisfied for every hour yielding an MINLP with 600 degrees of freedom (216 of them binary). A trial solution of the full, dynamic MINLP is solved in 27 CPU clock hours (on a $2.8 \mathrm{GHz}$ processor) using the branch and bound solver BONMIN. This optimization problem is run on a single CPU while parallelization of the branch and bound technique would lead to a significant reduction in clock time. While the solution is valid, the excessive solve time is untenable. In order to resolve this, an alternative formulation is used. This formulation decouples the dynamic and static components of the problem. Because steady state models are used for all equipment except the TES, the TES charge rate at each hour can be used as the only decision variable. Given a charge rate for a specific hour, static sub-problems can then be solved so as to 
report back their optimal solutions to the dynamic problem so that its objective function $(F)$ can

389 be computed. This technique requires solving thousands of static problems, but it reduces the 390 dynamic problem from a 600 variable problem to a 24 variable problem. Solution time is reduced 391 to an average of $30-40$ minutes.

This technique is diagrammed in Figure 10. As the figure illustrates, the decision variables for the dynamic problem $(U i)$ are fed to the static sub-problems (for each hour). When 394 these problems are solved, they report back the value of their objective function at their optimal 395 solutions $\left(f_{i}^{*}\right)$ so that the objective function of the dynamic problem $(F)$ can be computed. 396 Numerical gradients and Hessians of the dynamic problem are generated at each iteration.

\section{Static Problems}

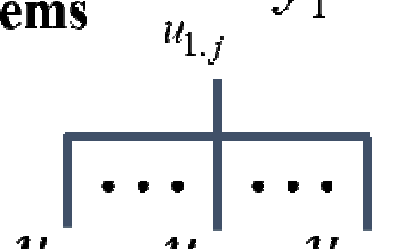

\section{Dynamic Problem}

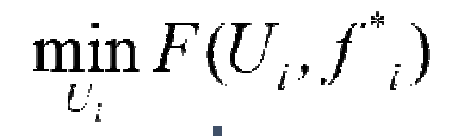

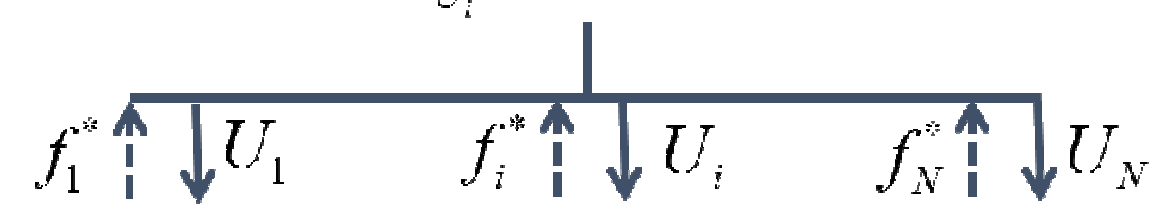

Figure 10: A diagram outlining the static / dynamic optimization problem decoupling.

In Figure 10, the decision variables to the dynamic problem $\left(U_{i}\right)$ are the TES charge rates $\left(Q_{T E S, i}\right)$. These rates have upper and lower limits. Positive values indicate charging the system, while negative values are discharging (36).

$$
-36 M W_{t h} \leq Q_{T E S, i} \leq 25 M W_{t h}
$$

The total energy in the TES must also remain within its bounds (37). 


$$
0 \leq E_{T E S, i} \leq 138 M W h_{t h}
$$

With the new problem formulation, the dynamic problem is given in (38). The static 404 constraints given must be satisfied for every time step $i$.

$$
\begin{gathered}
\min _{U_{i}} F \\
\text { s.t. (2)-(37) }
\end{gathered}
$$

405

406

407

The dynamic problem is formulated and solved in MATLAB using the fmincon solver with the SQP algorithm for both the dynamic and the static optimization problems. The results are presented in the next section.

\section{RESUlTS AND DISCUSSION}

The dynamic (with storage) and static (without storage) optimization problems are solved under three scenarios: 1-minimizing fuel costs only, 2-minimizing costs, where revenue can be obtained by selling excess power to the grid, 3-minimizing costs where power can be both bought and sold to and from the grid. When power is exported and imported, the selling prices used are the day-ahead market prices for Austin, Texas from the corresponding hours. The study consists of a one year period from using weather data from the national weather database for the Austin area [41].

The total power production for a one-week period is shown in (a) of Figure 11 and Figure 12. These plots also show the net power exported to the grid in (b) and the selling price of the power in (c). The plots show the scenarios where power can be sold to the grid and compare it to the total electrical load. In Figure 11, the electricity prices remain relatively flat, except for a few peaks in the afternoon. On Sunday and Friday afternoon, excess power is sold, but price differentials are not steep enough to justify using the TES to free up more electric generation capacity to sell even more power. When the prices rise significantly higher, as is the case on Monday and Wednesday, the TES is charged in the early morning. This frees up the capacity on the turbines so that more power can be sold later in the afternoon on those days. This is particularly important on Monday, when prices exceed \$200/MWh. 


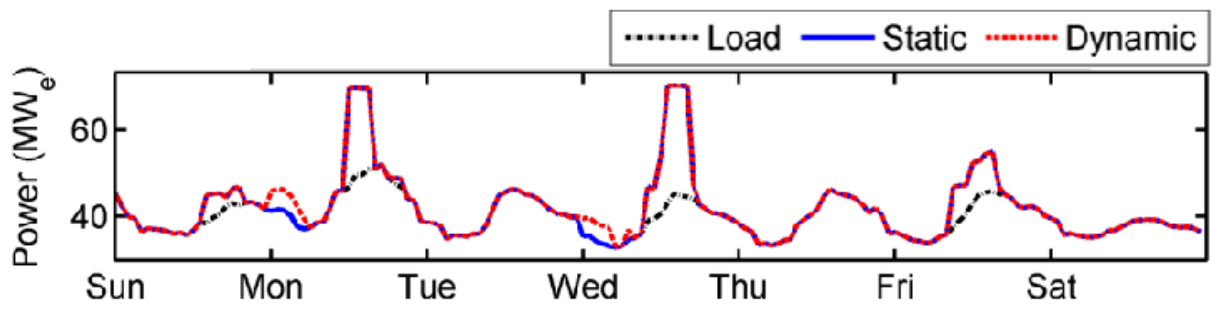

(a)

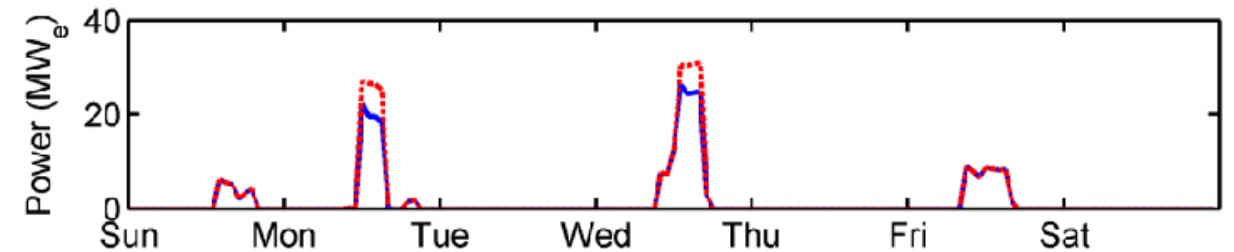

(b)

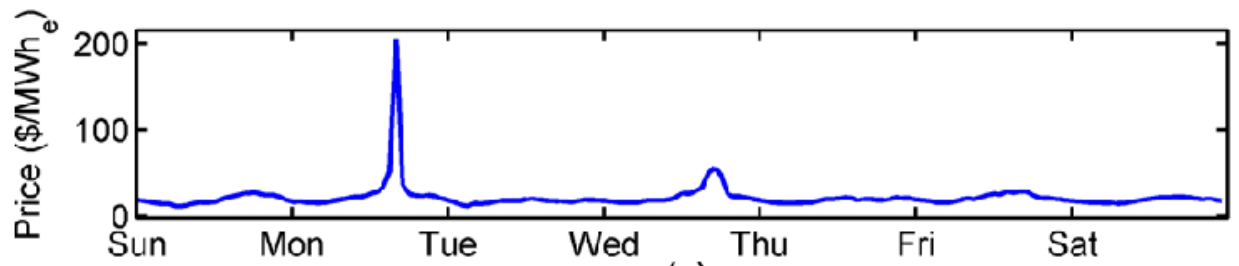

(c)

Figure 11: Total power production (a), net power sold (b), and electricity price (c) for a week in May. The figure shows the scenario where power can be sold to the grid.

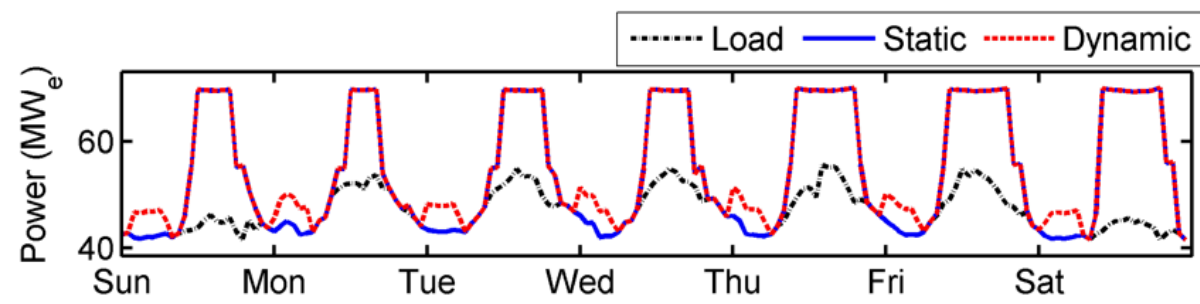

(a)

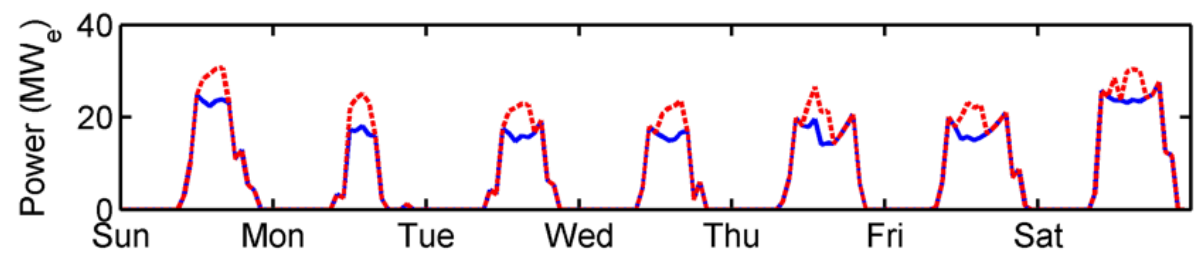

(b)

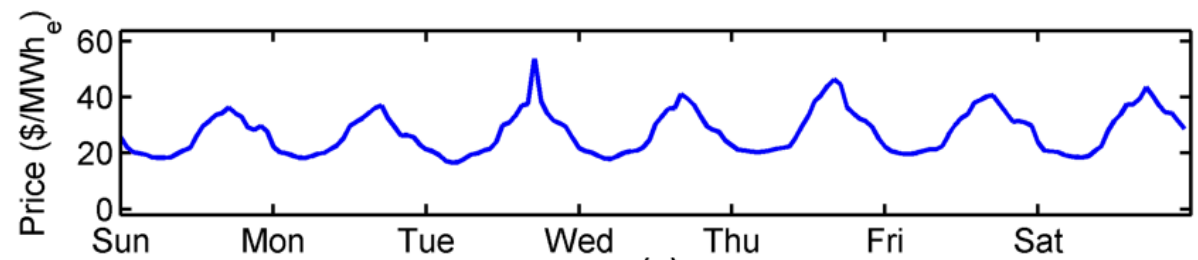

(c)

Figure 12: Total power production (a), net power sold (b), and electricity price (c) for a week in July. The figure shows the scenario where power can be sold to the grid. 
When electricity prices fluctuate with more regularity, the storage is used much more

433 frequently. In Figure 12, the storage is used every day of the week. While prices during this

434 particular week don't reach the same levels as in the previous figure, they oscillate enough to

435 justify charging the TES tank when prices are low so that the chiller electricity usage can be

436 minimized during peak hours when the prices rise.

437 The optimization problems, both static and dynamic, are non-convex. Therefore, the 438 solvers have a tendency to converge at local optima, which is undesirable. It is critical, therefore, 439 to use a good initial guess when solving the problem. The strategy for initializing the dynamic 440 optimization problem in this study is to assume that the storage charges during times when 441 electricity prices are low and discharges when the opposite is true.

442 The static and dynamic problems are solved for the entire year-long period for each 443 scenario. The results, showing the total yearly cost for each scenario are shown in Figure 13. As 444 the figure shows, there is a savings of about $\$ 250,000$ that can be obtained by optimizing the 445 system. In terms of only minimizing fuel usage (the No Sell scenario), storage has only a 446 marginal benefit. The efficiency that can be gained by shifting cooling loads from one time to 447 another is typically so small that it is offset by the storage losses. It is generally not beneficial to 448 use storage only to improve efficiency for this particular system. In general, energy storage is 449 only profitable when there is time of day pricing. For an isolated system that can meet peak 450 demand and with constant fuel prices, there is little incentive to install energy storage.

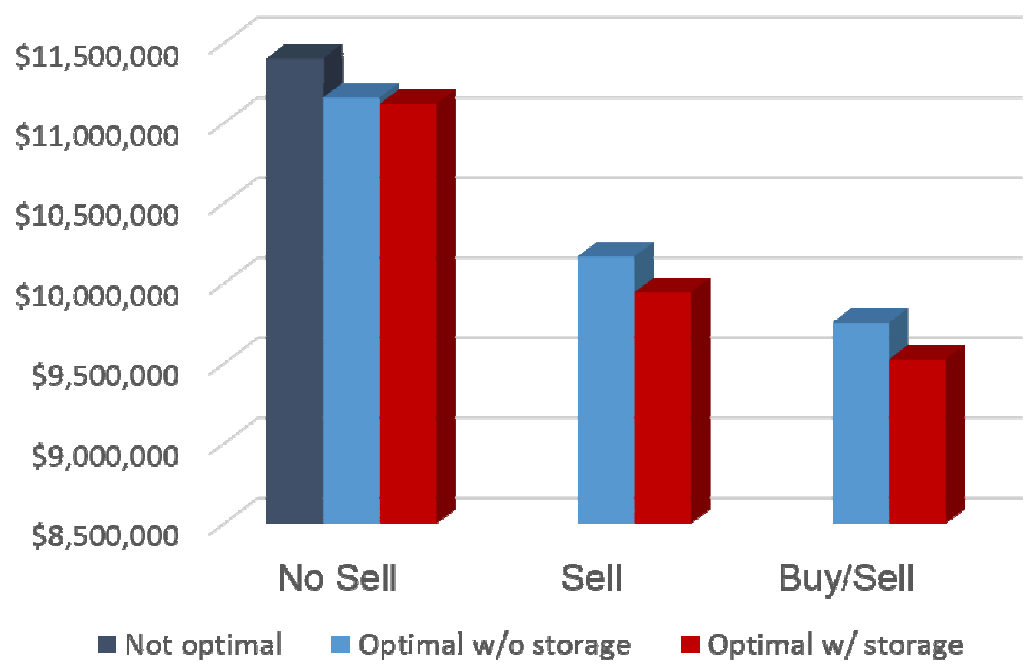

Figure 13: Summary of total operating costs for one year under various scenarios. 
Revenue from selling excess power helps to significantly offset fuel costs. When power can be sold to the grid, the costs are reduced by $\$ 1$ million when going from the no selling/no storage to selling/no storage. Compared to the latter scenario, the incorporation of TES further reduces costs by $2.2 \%$. The TES is particularly valuable when electricity prices are excessive, as it frees up electrical capacity by reducing the peak cooling load.

When power can be bought and sold from the grid, total costs are further reduced. As is sometimes the case, power can be imported at a lower cost than it can be generated. While the turbines must still be run to meet heating loads, their usage can be minimized by supplementing the electrical generation with imported power. When TES is used, arbitrage can be done. The TES can be charged when prices are low. When prices are high, the TES is discharged to reduce the campus electrical load. This provides excess electrical generation capacity so that more power can be sold. The savings from using storage are $2.3 \%$ as compared to the buy/sell scenario without storage.

As expected, optimization is more effective when constraints are relaxed. While there may be regulatory constraints for district energy systems to freely buy and sell power from the grid, the ability to do so can significantly offset operating costs. From the worst case to the best case, a total savings of $\$ 1.88$ million (16.5\%) is achieved. The results show that for this particular system, the benefit of TES is only fully realized when the system is allowed to participate in the electricity market.

It should be again noted that the costs discussed in this section are only fuel and electricity prices. No labor and other operational costs are included. The study also assumes the system can freely exchange electricity with the grid at wholesale market prices. This scenario is idealized as there may be other (non-technical) issues. For example, the system may be subject to 476 the rates of the local utility, which would typically be higher than wholesale market rates, for 477 buying electricity. When exporting power, there may be other regulatory hurdles to consider, 478 which would likely increase costs. From a purely technical point of view, however, the benefits 479 of using TES and participating in the open electricity market are clear. 


\section{CONCLUSIONS}

District energy and CHP systems offer many advantages. Because of the proximity to a source of heat (the waste heat from power production), meeting electrical and heating demands can be done very efficiently. District cooling provides a unique opportunity to introduce low cost TES. Because the economy of scale benefit is already in place with centralized cooling, TES can be readily integrated. This gives the system flexibility and can alleviate the cost of additional cooling equipment, as much of the peak demand can be shifted to off-peak periods.

Systems with coupled heating, cooling, and power generation are quite complex as there are many inter-relations between the varying pieces of equipment. There are also opportunities to optimize such systems. TES, while storing thermal energy, can be used to shift electrical loads, which can be integral if the system exchanges electricity with the grid. For this particular system, the benefits of TES from an efficiency standpoint are negligible. However, in terms of offsetting costs by participating the in the electricity market, the benefit of TES can be significant.

The ability to buy or sell power from an outside source give the district energy system additional degrees of freedom, allowing it to import power when electricity prices are low and to export when they are high. These degrees of freedom can be exploited through optimization, which finds the optimal values of decision variables so that some ideal objective is achieved. TES provides more degrees of freedom, giving the system the ability to shift loads temporally and take advantage of differences in efficiency or operating cost at different times. With the addition of TES, the problem becomes dynamic, and while the benefit of optimizing is greater, the difficulty also increases significantly. The dynamic problem can be simplified by breaking it into a series of static problems. This method allows the problem to be solved more efficiently so that real-time optimization can be performed.

With intermittent renewable technologies becoming more prevalent, the smart grid is being developed to enable efficient operation and two-way power flow. The smart grid provides new opportunities to optimize diverse energy systems. With district energy systems, the concept of the smart grid extends beyond electricity generation and can incorporate even more diverse types of equipment dealing with cooling or heating energy. These systems also provide ample opportunity to optimize and can be used to incorporate non-electrical energy storage (like TES), into a smart grid environment. 


\section{7. ACKNOWLEDGEMENTS}

512

The authors thank the University of Texas at Austin Utilities and Energy Management

513 Group as well as the University of Texas at Austin Office of Sustainability for access to 514 equipment, data, and technical expertise. This research work was supported by the National 515 Science Foundation (NSF) Graduate Research Fellowship and a grant from the University of 516 Texas Office of Sustainability. 


\begin{tabular}{|c|c|c|}
\hline Symbol & Description & Units \\
\hline$A$ & $\begin{array}{l}\text { Matrix with coefficients for quadratic terms in cooling } \\
\text { station auxiliary power model }\end{array}$ & - \\
\hline $\boldsymbol{B}$ & $\begin{array}{l}\text { Vector with coefficients for linear terms in cooling } \\
\text { station auxiliary power model }\end{array}$ & - \\
\hline$C$ & $\begin{array}{l}\text { Scalar with coefficients for constant terms in cooling } \\
\text { station auxiliary power model }\end{array}$ & - \\
\hline$C_{e}$ & Electricity price & $\$ / M_{e}$ \\
\hline$C_{f}$ & Fuel price & $\$ / \mathrm{kg}$ \\
\hline COP & Coefficient of performance & - \\
\hline$C_{p c}$ & $\begin{array}{l}\text { Average air heat capacity at lower temperatures at } \\
\text { constant pressure }\end{array}$ & $\mathrm{kJ} /(\mathrm{kgK})$ \\
\hline$C_{p h}$ & $\begin{array}{l}\text { Average air heat capacity at higher temperatures at } \\
\text { constant pressure }\end{array}$ & $\mathrm{kJ} /(\mathrm{kgK})$ \\
\hline$E_{T E S}$ & Energy stored in the TES & MWh \\
\hline$f$ & Objective function for static problem & $\$ / \mathrm{hr}$ \\
\hline$F$ & Objective function for dynamic problem & $\$$ \\
\hline $\boldsymbol{h}_{E C}$ & Economizer water specific enthalpy & $\mathrm{kJ} / \mathrm{kg}$ \\
\hline$h_{S, C O N D}$ & Steam turbine condenser steam specific enthalpy & $\mathrm{kJ} / \mathrm{kg}$ \\
\hline$h_{S, E X T}$ & Extraction steam specific enthalpy & $\mathrm{kJ} / \mathrm{kg}$ \\
\hline$h_{S H}$ & Superheated steam specific enthalpy & $\mathrm{kJ} / \mathrm{kg}$ \\
\hline$i$ & Subscript indicating time interval & - \\
\hline$j$ & Subscript indicating chiller & . \\
\hline$L_{C}$ & Total campus cooling demand & $\mathrm{MW}_{\text {th }}$ \\
\hline$L_{E}$ & Total campus electrical demand & $\mathrm{MW}_{\mathrm{e}}$ \\
\hline$L_{H}$ & Total campus heating demand & $\mathrm{kg} / \mathrm{s}$ \\
\hline$L H V$ & Lower heating value of fuel & $\mathrm{kJ} / \mathrm{kg}$ \\
\hline$M_{\text {cond }}$ & $\begin{array}{l}\text { Product of condenser heat exchanger coefficient and } \\
\text { heat exchange surface area }\end{array}$ & $\mathrm{kW} / \mathrm{K}$ \\
\hline$M_{\text {evp }}$ & $\begin{array}{l}\text { Product of evaporator heat exchanger coefficient and } \\
\text { heat exchange surface area }\end{array}$ & $\mathrm{kW} / \mathrm{K}$ \\
\hline $\boldsymbol{P}_{a}$ & Ambient air pressure (absolute) & bar \\
\hline $\boldsymbol{P}_{a 0}$ & Reference ambient air pressure & bar \\
\hline $\boldsymbol{P}_{\text {aux }}$ & $\begin{array}{l}\text { Electrical power consumed by cooling system } \\
\text { auxiliaries (cooling towers and pumps) }\end{array}$ & $\mathrm{MW}_{\mathrm{e}}$ \\
\hline $\boldsymbol{P}_{c h}$ & Electrical power consumed by chillers & $\mathrm{MW}_{\mathrm{e}}$ \\
\hline$P_{G T}$ & Gas turbine power output & $\mathrm{MW}_{\mathrm{e}}$ \\
\hline $\boldsymbol{P}_{\text {net }}$ & Power exchange to/from grid & $\mathrm{MW}_{\mathrm{e}}$ \\
\hline$P R$ & Gas turbine compression ratio & - \\
\hline$P_{S T}$ & Steam turbine power output & $\mathrm{MW}_{\mathrm{e}}$ \\
\hline$Q$ & Individual chiller cooling load & $\mathrm{MW}_{\text {th }}$ \\
\hline$q_{\text {cond }}$ & Rate of internal losses at the condenser & $\mathrm{MW}_{\text {th }}$ \\
\hline$q_{\text {evp }}$ & Rate of internal losses at the evaporator & $\mathrm{MW}_{\text {th }}$ \\
\hline$Q_{s}$ & Total station cooling load & $\mathrm{MW}_{\text {th }}$ \\
\hline$Q_{T E S}$ & TES charging rate & $\mathrm{MW}_{\text {th }}$ \\
\hline
\end{tabular}




\begin{tabular}{|c|c|c|}
\hline$Q_{T I C}$ & TIC cooling load & $\mathrm{MW}_{\mathrm{th}}$ \\
\hline $\boldsymbol{R}_{H}$ & Relative humidity' & $\%$ \\
\hline$T_{a 0}$ & Inlet air reference temperature & $\mathrm{K}$ \\
\hline $\boldsymbol{T}_{\text {cond }}$ in & Condenser water inlet temperature & $\mathrm{K}$ \\
\hline$T_{d}$ & Pre-combustion temperature in gas turbine & $\mathrm{K}$ \\
\hline$T_{D B}$ & Dry Bulb Temperature & $\mathrm{K}$ \\
\hline$T_{e}$ & Turbine exhaust temperature & $\mathrm{K}$ \\
\hline$T_{e, H R S G i}$ & Post duct burner HRSG air temperature & $\mathrm{K}$ \\
\hline$T_{\text {evp }}^{\text {out }}$ & Evaporator water outlet temperature & $\mathrm{K}$ \\
\hline $\boldsymbol{T}_{\boldsymbol{f}}$ & Post combustion (firing) temperature in gas turbine & $\mathrm{K}$ \\
\hline$T_{i}$ & Turbine inlet temperature & $\mathrm{K}$ \\
\hline$T_{W B}$ & Wet Bulb Temperature & $\mathrm{K}$ \\
\hline$u$ & Vector of decision variables for static problem & - \\
\hline $\boldsymbol{U}$ & Vector of decision variables for dynamic problem & - \\
\hline$W_{\text {air }}$ & Air mass flow rate (entering turbine) & $\mathrm{kg} / \mathrm{s}$ \\
\hline$W_{f, B R}$ & Fuel mass flow rate (entering auxiliary boiler) & $\mathrm{kg} / \mathrm{s}$ \\
\hline$W_{f, G T}$ & Fuel mass flow rate (entering turbine combustor) & $\mathrm{kg} / \mathrm{s}$ \\
\hline $\boldsymbol{W}_{f, H R S G}$ & Fuel mass flow rate (entering HRSG) & $\mathrm{kg} / \mathrm{s}$ \\
\hline$W_{g}$ & Gas turbine exhaust mass flow rate & $\mathrm{kg} / \mathrm{s}$ \\
\hline$W_{n}$ & Gas turbine air flow rate at nominal conditions & $\mathrm{kg} / \mathrm{s}$ \\
\hline$W_{S, C O N D}$ & Steam turbine condenser flow rate & $\mathrm{kg} / \mathrm{s}$ \\
\hline$W_{S, E X T}$ & Extraction steam flow rate & $\mathrm{kg} / \mathrm{s}$ \\
\hline$W_{S H, B R}$ & Auxiliary boiler steam flow rate & $\mathrm{kg} / \mathrm{s}$ \\
\hline$W_{S H, H R S G}$ & HRSG steam flow rate & $\mathrm{kg} / \mathrm{s}$ \\
\hline$W_{S H, t o t}$ & Total superheated steam flow rate & $\mathrm{kg} / \mathrm{s}$ \\
\hline$X$ & $\begin{array}{l}\text { Vector containing model inputs for cooling station } \\
\text { power consumption models }\end{array}$ & - \\
\hline$x_{c}$ & Lumped variable & - \\
\hline$x_{h}$ & Superheated steam specific enthalpy & $\mathrm{kJ} / \mathrm{kg}$ \\
\hline$\gamma_{c}$ & Low temperature ratio of specific heats & - \\
\hline$\gamma_{h}$ & High temperature ratio of specific heats & - \\
\hline$\delta$ & Binary decision variable & - \\
\hline$\Delta H_{F W}$ & HRSG feedwater heater heat duty & $\mathrm{MW}_{\text {th }}$ \\
\hline$\Delta P_{T I C}$ & Pressure drop across TIC & bar \\
\hline$\Delta t$ & Time interval & $\mathrm{hr}$ \\
\hline$\eta_{B R}$ & Boiler efficiency & - \\
\hline$\eta_{c}$ & Compressor efficiency & - \\
\hline$\eta_{c o m b, G T}$ & Gas turbine combustor efficiency & - \\
\hline$\eta_{c o m b, H R S G}$ & HRSG combustor efficiency & - \\
\hline$\eta_{H R S G}$ & HRSG efficiency & - \\
\hline$\eta_{t}$ & Turbine efficiency & - \\
\hline$\theta_{0}$ & Reference inlet guide vane angle & degrees \\
\hline$\theta_{I G V}$ & Inlet guide vane angle & degrees \\
\hline$\theta_{\max }$ & Maximum inlet guide vane angle & degrees \\
\hline
\end{tabular}




\section{Works Cited}

521 [1] Gao J, Xiao Y, Liu J, Liang W, Chen CLP. A survey of communication/networking in Smart Grids. Futur Gener Comput Syst 2012;28:391-404. doi:10.1016/j.future.2011.04.014.

[2] Markovic DS, Zivkovic D, Branovic I, Popovic R, Cvetkovic D. Smart power grid and cloud computing. Renew Sustain Energy Rev 2013;24:566-77. doi:10.1016/j.rser.2013.03.068.

[3] Alonso M, Amaris H, Alvarez-Ortega C. Integration of renewable energy sources in smart grids by means of evolutionary optimization algorithms. Expert Syst Appl 2012;39:551322. doi:10.1016/j.eswa.2011.11.069.

[4] Yilmaz "Muhittin, Dhansri" NR. "A Smart Grid Robust Optimization Framework." Complex Adapt Syst 2012 2012;12:301-6. doi:10.1016/j.procs.2012.09.075.

[5] Gonzalez FG. An Intelligent Controller for the Smart Grid. 2013 Conf Syst Eng Res 2013;16:776-85. doi:10.1016/j.procs.2013.01.081.

[6] Koohi-Kamali S, Tyagi VV, Rahim NA, Panwar NL, Mokhlis H. Emergence of energy storage technologies as the solution for reliable operation of smart power systems: A review. Renew Sustain Energy Rev 2013;25:135-65. doi:10.1016/j.rser.2013.03.056.

[7] Wade NS, Taylor PC, Lang PD, Jones PR. Evaluating the benefits of an electrical energy storage system in a future smart grid. Energy Policy 2010;38:7180-8. doi:10.1016/j.enpol.2010.07.045.

[8] Arce P, Medrano M, Gil A, Oró E, Cabeza LF. Overview of thermal energy storage (TES) potential energy savings and climate change mitigation in Spain and Europe. Appl Energy 2011;88:2764-74. doi:10.1016/j.apenergy.2011.01.067.

[9] Ehyaei MA, Mozafari A, Ahmadi A, Esmaili P, Shayesteh M, Sarkhosh M, et al. Potential use of cold thermal energy storage systems for better efficiency and cost effectiveness. Energy Build 2010;42:2296-303. doi:10.1016/j.enbuild.2010.07.013.

[10] Cole WJ, Powell KM, Edgar TF. Optimization and advanced control of thermal energy storage systems. Rev Chem Eng 2012;28:81-99. doi:10.1515/revce-2011-0018.

[11] Edgar TF, Powell KM. Energy intensification using thermal storage. Curr Opin Chem Eng 2015;9:83-8. doi:10.1016/j.coche.2015.11.002.

[12] Powell KM, Edgar TF. Modeling and control of a solar thermal power plant with thermal energy storage. Chem Eng Sci 2012;71:138-45. doi:10.1016/j.ces.2011.12.009.

[13] Powell KM, Edgar TF. Control of a large scale solar thermal energy storage system. Proc. 2011 Am. Control Conf., IEEE; 2011, p. 1530-5. doi:10.1109/ACC.2011.5991593.

[14] Powell KM, Cole WJ, Ekarika UF, Edgar TF. Optimal chiller loading in a district cooling system with thermal energy storage. Energy 2013;50:445-53. doi:10.1016/j.energy.2012.10.058.

[15] Powell KM, Edgar TF. An adaptive-grid model for dynamic simulation of thermocline thermal energy storage systems. Energy Convers Manag 2013;76:865-73. doi:10.1016/j.enconman.2013.08.043.

[16] Pirouti M, Bagdanavicius A, Ekanayake J, Wu J, Jenkins N. Energy consumption and economic analyses of a district heating network. Energy n.d. doi:10.1016/j.energy.2013.01.065.

[17] Sanaei SM, Nakata T. Optimum design of district heating: Application of a novel methodology for improved design of community scale integrated energy systems. Energy 2012;38:190-204. doi:10.1016/j.energy.2011.12.016. 
566

[18] Sperling K, Möller B. End-use energy savings and district heating expansion in a local renewable energy system - A short-term perspective. Appl Energy 2012;92:831-42. doi:10.1016/j.apenergy.2011.08.040.

[19] Kapoor K, Powell K, Cole W, Kim J, Edgar T. Improved Large-Scale Process Cooling Operation through Energy Optimization. Processes 2013;1:312-29. doi:10.3390/pr1030312.

[20] Adhikari RS, Aste N, Manfren M. Optimization concepts in district energy design and management - A case study. 2011 2nd Int Conf Adv Energy Eng 2012;14:1386-91. doi:10.1016/j.egypro.2011.12.1106.

[21] Chan ALS, Chow T-T, Fong SKF, Lin JZ. Performance evaluation of district cooling plant with ice storage. Energy 2006;31:2750-62. doi:10.1016/j.energy.2005.11.022.

[22] Henning D, Amiri S, Holmgren K. Modelling and optimisation of electricity, steam and district heating production for a local Swedish utility. Eur J Oper Res 2006;175:1224-47. doi:10.1016/j.ejor.2005.06.026.

[23] Powell KM, Hedengren JD, Edgar TF. Dynamic optimization of a hybrid solar thermal and fossil fuel system. Sol Energy 2014;108:210-8. doi:10.1016/j.solener.2014.07.004.

[24] Hedengren JD, Shishavan RA, Powell KM, Edgar TF. Nonlinear modeling, estimation and predictive control in APMonitor. Comput Chem Eng 2014;70:133-48. doi:10.1016/j.compchemeng.2014.04.013.

[25] Nuytten T, Claessens B, Paredis K, Van Bael J, Six D. Flexibility of a combined heat and power system with thermal energy storage for district heating. Appl Energy 2013;104:583-91. doi:10.1016/j.apenergy.2012.11.029.

[26] Verda V, Colella F. Primary energy savings through thermal storage in district heating networks. Energy 2011;36:4278-86. doi:10.1016/j.energy.2011.04.015.

[27] Sun Y, Wang S, Xiao F, Gao D. Peak load shifting control using different cold thermal energy storage facilities in commercial buildings: A review. Energy Convers Manag 2013;71:101-14. doi:10.1016/j.enconman.2013.03.026.

[28] Henze GP, Biffar B, Kohn D, Becker MP. Optimal design and operation of a thermal storage system for a chilled water plant serving pharmaceutical buildings. Energy Build 2008;40:1004-19. doi:10.1016/j.enbuild.2007.08.006.

[29] Harvey S, Carcasci C, Berntsson T. Gas turbines in district heating combined heat and power systems: influence of performance on heating costs and emissions. Appl Therm Eng 2000;20:1075-103. doi:10.1016/S1359-4311(99)00076-9.

[30] Rolfsman B. Combined heat-and-power plants and district heating in a deregulated electricity market. Appl Energy 2004;78:37-52. doi:10.1016/S0306-2619(03)00098-9.

[31] Basu M. Artificial immune system for combined heat and power economic dispatch. Int J Electr Power Energy Syst 2012;43:1-5. doi:10.1016/j.ijepes.2012.05.016.

[32] Chen C-L, Lee T-Y, Jan R-M, Lu C-L. A novel direct search approach for combined heat and power dispatch. Int J Electr Power Energy Syst 2012;43:766-73. doi:10.1016/j.ijepes.2012.05.033.

[33] Mohammadi-Ivatloo B, Moradi-Dalvand M, Rabiee A. Combined heat and power economic dispatch problem solution using particle swarm optimization with time varying acceleration coefficients. Electr Power Syst Res 2013;95:9-18.

[34] Sashirekha A, Pasupuleti J, Moin NH, Tan CS. Combined heat and power (CHP) economic dispatch solved using Lagrangian relaxation with surrogate subgradient 
multiplier updates. Int J Electr Power Energy Syst 2013;44:421-30. doi:10.1016/j.ijepes.2012.07.038.

[35] Majid MAA, Nasir M, Waluyo J. Operation and Performance of a Thermal Energy Storage System: A Case Study of Campus Cooling using Cogeneration Plant. Energy Procedia 2012;14:1280-5. doi:10.1016/j.egypro.2011.12.1089.

[36] Cole WJ, Rhodes JD, Powell KM, Edgar TF. Turbine inlet cooling with thermal energy storage. Int J Energy Res 2014;38:151-61. doi:10.1002/er.3014.

[37] Gordon J., Ng KC, Chua HT. Centrifugal chillers: Thermodynamic modelling and a diagnostic case study. Int J Refrig 1995;18:253-7. doi:10.1016/0140-7007(95)96863-2.

[38] Gordon JM, Ng KC. A general thermodynamic model for absorption chillers: Theory and experiment. Heat Recover Syst CHP 1995;15:73-83. doi:10.1016/0890-4332(95)90038-1.

[39] Kim JS, Powell KM, Edgar TF. Nonlinear model predictive control for a heavy-duty gas turbine power plant. 2013 Am. Control Conf., IEEE; 2013, p. 2952-7. doi:10.1109/ACC.2013.6580283.

[40] Powell KM, Sriprasad A, Cole WJ, Edgar TF. Heating, cooling, and electrical load forecasting for a large-scale district energy system. Energy 2014;74:877-85. doi:10.1016/j.energy.2014.07.064.

[41] Team NWSCIW. National Weather Service Climate n.d. 